\title{
A APRENDIZAGEM DE LÍNGUA ESTRANGEIRA NA ESCOLA REGULAR: DESAFIOS E POSSIBILIDADES
}

\author{
Eric Brun \& Milenna Brun* \\ Paloma Marques**
}

RESUMO: Neste artigo, partindo dos pressupostos de que a aprendizagem de línguas estrangeiras é importante para o desenvolvimento integral do indivíduo e de que o ensino precoce de línguas estrangeiras pode e deve ser realizado na escola regular, apresentamos alguns de seus desafios e possibilidades. $\mathrm{O}$ ensino precoce de línguas estrangeiras na escola é justificado numa perspectiva humanista, socioafetiva e neurolingüística e seus objetivos educativos, culturais e lingüísticos são discutidos. Enfim, são propostas alternativas para as dificuldades freqüentemente encontradas na prática dos professores de línguas baseadas em projeto piloto atualmente em desenvolvimento.

PALAVRAS-CHAVE: Ensino de segunda língua, Ensino de línguas, Educação.

RESUMÉ: Dans cet article, croyant que l'apprentissage de langues étrangères est important pour le développement intégral de l'individu et que l'enseignement précoce de langues étrangères peut et doit être fait à l'école, nous présentons quelques uns de ces défis et possibilités. L'enseignement précoce de langues étrangères est justifié dans une perspective humaniste, socioaffective et neurolinguistique et nous $y$ analysons ses objectifs éducatifs, culturels et linguistiques. Enfin, nous proposons des alternatives aux difficultés fréquemment rencontrées dans la pratique des enseignants de langues, basées sur un projet pilote en cours d'implantation.

MOTS CLÉ: Enseignement de langues étrangères, Enseignement de langues, Education.

*Universidade Estadual de Feira de Santana

**Universidade Católica do Salvador 


\section{INTRODUÇÃO}

Qual a melhor escola de inglês para os nossos filhos? Qual a idade adequada para se começar a aprender línguas estrangeiras? Tais inquietações parentais se transformam corriqueiramente em consultas a especialistas no campo do ensino de línguas. Como professores de línguas estrangeiras, recebemos freqüentemente solicitações de informações acerca das possíveis vantagens e desvantagens da aprendizagem de línguas na infância. Neste artigo, buscaremos atender a esta crescente demanda de esclarecimento e apresentar os desafios e possibilidades da aprendizagem precoce de línguas estrangeiras. Partimos dos pressupostos de que (1) a aprendizagem de línguas estrangeiras é importante para o desenvolvimento integral do indivíduo; (2) a aprendizagem precoce de línguas estrangeiras é possível e desejável; e, (3) o ensino de línguas estrangeiras pode e deve ser realizado na escola regular.

Embora ainda não sejam aceitas com grande facilidade, as duas primeiras premissas não seriam tão rejeitadas como a terceira, que é geralmente contemplada com muita descrença por parte de muitos colegas e da maioria dos pais. A incredulidade dos pais não é de todo infundada, porém não é mais cabível que profissionais deste campo permaneçam céticos quanto às possibilidades de tal ensino e, conseqüentemente, desistam de criar alternativas para viabilizá-lo.

Tal ceticismo compartilhado por pais, professores e diretores de escola é profundo e perigoso. Ele está relacionado ao mito de que "língua estrangeira não se aprende na escola e sim no cursinho". Este mito instituído há décadas, no ensino de línguas estrangeiras, no país, tem sido a peça chave para igualar os contextos público e privado no que diz respeito ao ensino de línguas estrangeiras. De fato, enquanto em outras disciplinas existe uma grande diferença na qualidade do ensino e no conseqüente desempenho dos alunos, nas aulas de língua estrangeira, os resultados das escolas particulares são semelhantes aos das escolas públicas. Ambas têm 
sido incapazes de aceitar o desafio proposto tanto pela nova lei de diretrizes e bases da educação quanto pelo mundo contemporâneo. Retardam assim a necessária desmontagem do perverso fenômeno da paraescolarização do ensino de línguas estrangeiras ao qual estamos tão habituados no país.

Tal desmontagem, contudo, é imprescindível porque, no mundo atual, educar deve corresponder a contribuir para a construção da identidade de cada indivíduo. A escola do futuro, segundo Edgar Morin (2000, p.49):

[...] deveria oferecer um ensino primeiro e universal tratando da condição humana. Estamos na era planetária; uma aventura comum leva os humanos onde que eles estejam. Devem se reconhecer na sua humanidade comum e, no mesmo tempo reconhecer a diversidade tanto individual que cultural.

É isso que está em jogo atualmente: a aprendizagem da tolerância através das diferenças lingüísticas e culturais para aniquilar os preconceitos.

A criança já tem a consciência mais ou menos desenvolvida de que existem outras línguas, outros países e outras etnias no mundo através do rádio, da televisão, da música, das conversas de adultos, do turismo, do cinema, etc. Portanto, falar da diversidade e no mesmo tempo das semelhanças no resto do planeta é uma maneira de entender melhor a sua realidade. $O$ ensino de línguas e culturas estrangeiras prepara a criança à complexidade das comunidades humanas desse planeta e do ser humano aproximando-a das outras comunidades estrangeiras longínquas. Este ensino luta, assim, contra o afastamento geográfico de algumas comunidades escolares trazendo um sentimento de identificação universal. A criança pode entender que: "as assimilações de uma cultura para a outra são enriquecedoras" (MORIN, 2000, p. 61) e assim falar da compreensão universal pode levar a falar de uma compreensão local com as comunidades nativas do Brasil. O ensino precoce de língua estrangeira é o aprender a [...] viver, dividir, comunicar também 
como humanos do planeta Terra. Não apenas ser de uma cultura, mas também ser terrestre (PORCHER E GROUX, 1998, p. 82).

A fim de atingir tais objetivos, a Comunidade Européia incluiu o ensino precoce de línguas como parte das suas novas diretrizes educativas. Infelizmente, no Brasil, embora a nova Lei de Diretrizes e Bases da Educação assegure um lugar de destaque para o ensino de línguas estrangeiras, ela apenas prevê tal ensino a partir da $5^{a}$ série. Esta parece ser uma das poucas falhas dos PCNs ocorrida não por razões teóricas, mas por evidentes questões políticas e práticas: isentar o governo de oferecer o ensino de língua estrangeira nos primeiros anos da educação fundamental.

Em muitos países, os sistemas educativos propõem o ensino de línguas a partir dos 7 anos de idade. No Canadá, particularmente no Quebec, o ensino bilíngüe (ministrado em inglês e francês) é muito pesquisado e difundido. Na Europa em geral, o ensino de língua está incluído no currículo do ensino fundamental há muito tempo já que:

[...] os alunos do Luxemburgo aprendem uma primeira língua estrangeira com 6 anos (o alemão) e uma segunda língua estrangeira com 7 anos (o francês). Os alunos irlandeses seguem um currículo bilíngüe (irlandêsinglês) durante a escolaridade toda (PORCHER e GROUX, 1998, p. 29).

A Itália, a Espanha e a Áustria têm projetos pilotos propondo um ensino precoce para crianças de 3 anos. Em 1998, a França definiu a competência oral como objetivo principal para o ensino de língua estrangeira, no ensino fundamental, através de uma abordagem interdisciplinar e conhecimentos transversais.

\section{O ENSINO PRECOCE DE LÍNGUAS ESTRANGEIRAS}

O ensino precoce de línguas estrangeiras na escola se justifica numa perspectiva humanista. Ele representa a possibilidade de oferecer às crianças alternativas lingüísticas e culturais na 
abordagem da complexidade do mundo em relação à língua franca que se tornou o inglês. Quando Jean-Claude Beacco (2003, p. 18) analisa a elaboração das políticas lingüísticas na Europa, ele afirma que:

[...] as políticas lingüísticas educacionais devem definir um projeto coerente para valorizar e desenvolver os repertórios plurilingüísticos dos cidadãos.

Defendendo a pluralidade lingüística, ele enfoca mais a dimensão humana do que os aspectos pragmáticos (necessidade e utilização da língua numa visão meramente instrumental) da aprendizagem de línguas estrangeiras.

Ensinar línguas estrangeiras significa oferecer à criança a possibilidade de descobrir um outro modo de tratamento interpessoal, outro modo de se relacionar com os temas universais tais como a morte, a vida, a religião, a liberdade, o poder, as leis, a escola, a família, os jogos, etc.; portanto, tal escolha segue uma lógica educadora e humanista, visto que os objetivos de todo sistema institucional de educação básica são de proporcionar ao mundo futuros cidadãos planetários responsáveis e cívicos.

Em termos neurolingüísticos, a aprendizagem precoce de línguas também é justificada. Claude Hagège (2001) afirma que "os bebês são capazes de perceber uma grande diversidade de sonoridades. Mas têm também um verdadeiro desejo de reprodução".

$\mathrm{O}$ autor continua assegurando que:

Por um outro lado, algumas consoantes (h e $\mathrm{r}$ vibrado especialmente) muito utilizadas nas outras línguas, inclusive vizinhas, não existem no francês contemporâneo. Esta estreiteza do espetro acústico e a dificuldade de pronunciar alguns sons justificam a aprendizagem precoce das línguas estrangeiras.

Dominique Groux (2003, p. s24) lembra que várias pesquisas apontam a existência de uma vantagem no plano intelectual ligado 
ao desenvolvimento da competência bilíngüe oriunda de "uma grande flexibilidade cognitiva resultando do bábito de passar de um sistema de simbolos para outro". Para um cérebro jovem, a aquisição de duas ou três línguas não é mais difícil que a de uma só. Tradução e “ensino" são desnecessários, pois a língua estrangeira é adquirida espontaneamente até os 6 ou 7 anos de idade. Para Claude Hagège (1996, p. 22):

[...] os hábitos articulatórios adquiridos na infância na língua primeira são gestos sociais [...] Por ser limitadas ao aparelho que vai dos lábios à laringe $[\ldots]$ as articulações dos sons que constituem a face fônica das línguas humanas são condutas gestuais.

O autor continua lembrando (ibidem, 1996, p. 25) que:

[...] a criança aprende a falar muito depois que ela aprende a ouvir. E é essa precocidade da audição, tanto quanto a sua riqueza de abertura aos mais variados sons que é preciso explorar na educação bilíngüe.

As oposições sonoras que não existem no ambiente lingüístico oral da criança se tornam cada vez menos sensíveis para o seu ouvido. Essa recessão explica-se provavelmente porque a ausência de estímulo no ambiente induz uma esclerose das sinapses correspondentes.

Daniel Modard apresenta razões que justificam o ensino precoce de línguas: uma exposição mais longa aos conteúdos lingüísticos, plasticidade dos órgãos fonatórios, ausência de inibição e de fenômenos de bloqueio. Modard (2000) defende a idéia de que a aprendizagem, na primeira infância, é facilitada devido a uma melhor percepção dos fonemas antes de 6/7 anos, ao crescimento cerebral, que ocorre até os 6 anos, e ao declínio dos processos de imitação que acontece a partir de 8 anos. E, já em 1988, Titone afirmava que a educação lingüística deveria fazer parte da formação geral da criança, visto que contribuía para uma 
consciência metalingüística capital.

Portanto, inúmeras pesquisas comprovam que é possível ensinar línguas para crianças mesmo antes da alfabetização, pois a aprendizagem de línguas estrangeiras não atrapalha a aprendizagem da língua materna (muito pelo contrário, crianças bilíngües desenvolvem sensivelmente suas habilidades metalingüísticas) e, biologicamente, o espectro auditivo e articulatório na primeira infância ainda é bastante flexível. Mas, onde este ensino deve ocorrer?

\section{O ENSINO DE LÍNGUAS ESTRANGEIRAS NA ESCOLA}

O texto dos Parâmetros Curriculares Nacionais responde à tal questionamento de forma inequívoca: "o ensino de línguas estrangeiras é função da escola, e é lá que deve ocorrer”. (PCNs, p. 19). Tentemos esclarecer as razões de uma afirmação tão categórica.

O ensino de línguas estrangeiras, na escola, tem três tipos de finalidades: (1) educativas: saber ser; (2) culturais: saber - saber conviver; e (3) lingüísticas: saber fazer.

Os objetivos educativos são indubitavelmente os mais importantes porque estão relacionados com a ética, que deve ser considerada elemento universal, subjacente e definidor das relações intersociais e interpessoais.

As questões éticas se tornaram, nos últimos anos, uma preocupação maior no conjunto da sociedade tanto devido a novos paradigmas e formas de organização quanto à intensificação do contato e conseqüentes conflitos entre os povos. $O$ mundo virtual sem lei propiciado pela Internet, faroeste da modernidade; as descobertas genéticas e possibilidades magníficas ou monstruosas que delas podem surgir; as urgências ecológicas e as dúvidas pertinentes sobre a sociedade da informação nos têm forçado a proceder a uma profunda revisão de valores morais, mas acima de tudo a refletir sobre princípios éticos.

Conseqüentemente, uma educação ética se torna necessária na 
medida em que possibilita uma reflexão sobre valores do mundo e serve de base para uma reflexão pessoal e para a construção de um mundo novo. Hoje talvez seja este o desafio filosófico e prático essencial dos sistemas educativos, particularmente no ensino de línguas. A escola, respondendo a uma demanda do social e também do individual, tenta deste modo recuperar uma função educativa propriamente dita e não apenas de ensino, ou transmissão e construção de conhecimento. No mundo atual, educar deve corresponder a contribuir para a construção da identidade de cada indivíduo, ou seja, para a formação de cidadãos com identidade própria, mas que vivem com outros, diferentes de si.

Especificamente no campo do ensino de línguas e culturas estrangeiras, desde a década de 80 a denominada abordagem comunicativa tem sido privilegiada. Segundo esta abordagem, aprender uma língua estrangeira é antes de tudo aprender a comunicar, ou seja, comunicando em língua estrangeira, o aluno aprende a se servir desta língua. Neste tipo de abordagem, (1) os problemas lingüísticos são teoricamente tratados apenas quando representam um obstáculo à comunicação, e (2) as questões (inter)culturais ganham relevo de caráter sobretudo pragmático. Porém, quando a língua é considerada apenas como possibilidade de gestão do real, e a comunicação que, como encontro da alteridade, deveria ser via de enriquecimento mútuo, é reduzida à construção de um saber e de um saber fazer, o espaço da aula de língua estrangeira promove, inversamente às expectativas, uma evacuação de uma reflexão ética. É exatamente isto que acontece nos cursinhos de língua.

A aprendizagem de língua estrangeira que, na escola, deve ocorrer de forma interdisciplinar com os conteúdos de história, geografia, ciências naturais, artes e educação física, não é apenas um exercício intelectual de aprendizagem de formas e estruturas lingüísticas em um código diferente. Por razões éticas, o ensino de línguas, na escola, se diferencia radicalmente do que é praticado nos cursinhos de línguas porque no espaço da escola regular não podemos compreender a língua apenas como um "instrumento" 
de comunicação, disponível para ser usado, como um martelo ou um computador.

A escola deve compreender a natureza sociointeracional da linguagem, isto é, de que quando usamos linguagem, nós o fazemos de algum lugar determinado social e historicamente. Em outras palavras, os valores dos interlocutores são intrínsecos aos processos de uso da linguagem, e os significados são construídos socialmente.

Por isso, a aprendizagem de línguas deve ser uma experiência de vida que possibilite a ação discursiva no mundo.

Além disso, a sala de aula de língua estrangeira é o lugar por excelência do encontro com a diferença, do movimento em direção à descoberta do outro através da descoberta de si mesmo. É claro que é o lugar até certo ponto incômodo da estrangeiridade, o lugar do estranho, do diferente onde os alunos se deparam, se confrontam com o novo, se apaixonam pelo novo, ou rejeitam o novo... A língua estrangeira e a cultura estrangeira também se caracterizam por serem vetores capazes de conduzir o aluno à prática da construção do binômio identidade/alteridade (descoberta de si mesmo através da descoberta do outro).

Três aspectos que dizem respeito à identidade são particularmente evocados na situação de aprendizagem e ensino de línguas: em primeiro lugar, a necessidade de unidade e de coerência interna que é desestabilizada pelo questionamento dos valores; em seguida, o sentimento de diferença que é essencial para a conscientização da identidade; e, enfim, o sentimento de ruptura com a realidade externa à classe.

A aprendizagem de línguas estrangeiras vai permitir um movimento de encontro em direção ao outro, estrangeiro, mas, sobretudo, ao outro como indivíduo dentro de uma sociedade com a qual ele pode ou não partilhar a mesma forma de agir, de sentir e de pensar. No processo de aprendizagem de línguas, preconceitos e estereótipos podem constituir objetos privilegiados para uma abordagem intercultural permitindo que o aluno os ultrapasse $\mathrm{e}$ consiga enxergar seu caráter parcial e caricatural. 
A aprendizagem de línguas estrangeiras deve servir como referência para os alunos pela sua condição de cidadão em formação em um mundo onde ainda existe o fenômeno da guerra. Ao entender o outro, o aluno aprende mais sobre si mesmo e sobre um mundo plural, marcado por valores culturais diferentes e maneiras diversas de organização política e social.

Enquanto os objetivos educacionais explícitos são exclusividade da escola, os objetivos culturais fazem parte também das preocupações dos cursinhos de língua. Contudo, como já explicamos, no contexto extra-escolar, a preocupação é meramente pragmática e não visa necessariamente promover uma apreciação dos costumes e valores de outras culturas, contribuindo para o desenvolvimento de uma competência intercultural.

Ora, no que tange o ensino de línguas estrangeiras, o principal objetivo cultural da escola é exatamente o desenvolvimento dessa competência intercultural, visto que ela representa uma estratégia para gerenciar a heterogeneidade cultural, que tem sido intensificada na maioria das sociedades como conseqüência da globalização, não apenas econômica mais também de valores.

A abordagem intercultural, particularmente originada na problemática da imigração e na necessidade premente de incumbir a educação com o papel de lutar contra atitudes intolerantes, racistas e discriminatórias, se concentra nas estratégias utilizadas por um estrangeiro para gerenciar as discrepâncias entre suas ações e interpretações e aquelas presentes no contexto e/ou na comunidade que está sendo descoberta por ele. Esta abordagem pretende responder ao desafio das nossas sociedades plurais a partir de uma conscientização sobre atitudes e representações sobre si mesmo e sobre o outro, sobre culturas de filiação e de adoção. Por esta razão a educação intercultural somente tem sentido se tiver projeção na estrutura social, integrando-se em discursos que ultrapassam o âmbito educacional, ou seja, exercendo a função essencial da escola: refletir e transformar a sociedade.

Assim, enquanto nos cursinhos os objetivos culturais se restringem ao saber sobre; na escola, eles devem ser ampliados para 
o saber conviver.

Enfim, os objetivos lingüísticos são semelhantes em ambos contextos e talvez sejam mais conhecidos: permitir uma percepção crítica da natureza da língua, desenvolver maior consciência do funcionamento da língua e da cultura materna e desenvolver habilidades comunicativas abrindo acesso às informações.

Diante do exposto, parece fundamentada a inclusão do ensino precoce de línguas estrangeiras na escola devido não somente à importância deste processo de aprendizagem, mas também por ser um vetor de desenvolvimento psicossocial do indivíduo.

Porém, nos resta ainda contemplar o problema central: ainda que estejamos convencidos das vantagens do ensino de línguas na escola, continuamos sem acreditar nas possibilidades reais de tal empreendimento.

\section{O ENSINO DE LÍNGUAS ESTRANGEIRAS NA ESCOLA: DESAFIOS E ALTERNATIVAS}

Relacionamos abaixo motivos freqüentes proferidos por pais e professores para justificar a inviabilidade do ensino e da aprendizagem de línguas estrangeiras na escola regular:

1. Não há livro didático adotado.

2. A carga horária é insuficiente.

3. Os professores não são formados adequadamente.

4. Só há uma professora de língua estrangeira para todas as turmas.

5. Não há sala de língua estrangeira.

6. Não existem oportunidades para a prática.

7. Os alunos têm níveis diferentes.

8. A escola não dá valor (não há reprovação).

9. As crianças não dão valor.

10. Os pais não aprenderam línguas na escola e não acreditam que tal aprendizagem seja possível. 
Então, considerando que existem relatos de experiências bem sucedidas de ensino de língua estrangeira na escola regular tanto no exterior como no Brasil, e também levando em conta estas dificuldades, propomos alternativas para tais dificuldades ${ }^{1}$ :

Livros didáticos para o ensino de crianças estão disponíveis nas editoras especializadas, inclusive com versões específicas para crianças brasileiras. Como o material é relativamente caro, a adoção de uma série didática pode ser realizada pela escola e não por cada família. Esta prática já acontece, por exemplo, no Curso de Licenciatura em Língua Inglesa da UEFS. Os livros didáticos foram adquiridos pela Biblioteca Universitária e os alunos os utilizam em regime de empréstimo longo durante todo o semestre.

A carga horária de uma hora semanal realmente é insuficiente para a aprendizagem de línguas estrangeiras, que requer uma certa quantidade e freqüência de input. É imprescindível um esforço para aumentar a carga horária de língua estrangeira para pelo menos duas horas semanais. Porém, atendendo as diretrizes curriculares que sugerem o ensino através de temas transversais e interdisciplinares, aulas de outras disciplinas podem ser utilizadas para complementar os conteúdos lingüísticos e culturais. Por exemplo, nas aulas de informática os alunos podem navegar em sites anglofones, exercitar inglês em Cdroms especializados e organizar projetos de inglês.

A formação dos professores é um elemento crucial neste processo. É necessário que a contratação de professores seja realizada a partir de conhecimentos sólidos tanto da língua estrangeira quanto da metodologia de ensino. Muitas escolas continuam contratando professores nativos sem formação específica como professores de língua, e vice-versa, professores licenciados sem a adequada competência lingüística. Contudo, se a formação continuada de professores de língua era dificultada no passado, atualmente algumas universidades já oferecem cursos de pós-graduação na área, a exemplo da UEFS que propôs em 2001 o primeiro Curso de Especialização em Ensino de Língua Inglesa da Bahia. Outras propostas de formação como aquela oferecida pela Cultura Inglesa em convênio com o Governo do Estado, ou ainda 
Projetos de Extensão Universitária (Palle na UEFS; Instituto de Letras na UFBa) são alternativas para a reciclagem de professores. As escolas que realmente se interessam pela formação de seus professores podem se associar e contratar consultores especializados para desenvolver projetos adaptados às suas realidades. Mesmo as escolas públicas podem contar com tais serviços caso busquem o apoio das universidades públicas.

Como geralmente as aulas de língua estrangeira não preenchem a carga horária dos professores contratados, eles devem assumir uma grande quantidade de turmas e ficam responsáveis pela totalidade de alunos de uma série, às vezes de toda uma escola. A contratação de estagiários ou projetos de convênio a longo prazo com Cursos de Licenciatura poderiam aliviar a sobrecarga de trabalho dos professores permitindo-lhes tempo para sua formação e para a elaboração de aulas e atividades.

Habitualmente as escolas não se preocupam em oferecer um espaço específico para o ensino de línguas estrangeiras. Isto acontece até na universidade. A sala de aula de língua estrangeira requer elementos ambientais peculiares: acústica adequada para as atividades de compreensão oral, equipamento de som permanente, cadeiras que possam ser facilmente deslocadas para atividades em grupos e pares, entre outros. É comum visitarmos escolas com elaborados laboratórios de informática, modernas quadras de esporte, sala de artes plásticas arrojadas, porém sem sala específica para o ensino de línguas. Nestes casos, as razões para a inadequação não estão relacionadas à aspectos financeiros.

A criação de oportunidades de prática lingüística extra-classe é uma tarefa simples. Muitas escolas já demonstraram soluções alternativas para aumentar o input: músicas e leitura de estórias nos intervalos, círculo de desenhos animados no recreio, etc.

Os alunos estão nivelados na educação infantil. O desnivelamento só começa porque muitas escolas não oferecem o ensino de línguas estrangeiras, contribuindo para a paraescolarização das crianças que são matriculadas pelos pais em cursinhos de idiomas. Rapidamente, nos $3^{\circ}$ ou $4^{\circ}$ anos, as turmas já apresentam 
níveis variados dificultando o ensino. A solução é tão óbvia quanto simples: adoção do ensino precoce de línguas enquanto todas as crianças são iniciantes. Nesse contexto, as transferências serão easos exeça.

O valor da aprendizagem só será incorporado pelos alunos, caso o seja também pelos adultos. É importante que as crenças de pais e professores sejam revisitadas. Isto porque a teoria afirma que é desejável. A prática mostra que, com criatividade, é possível. A nossa experiência pessoal nos lembra outra coisa... Mas será que realmente ainda acreditamos que tudo o que aconteceu conosco na escola vai ter que se repetir com as novas gerações? Esperamos sinceramente ter contribuído se não para modificar, ao menos para abalar a crença daqueles que ainda pregam a inviabilidade do ensino precoce de línguas estrangeiras na escola regular.

\section{NOTAS}

${ }^{1}$ Atualmente um projeto piloto de ensino de inglês nestes moldes com turmas de $1^{\circ}$ e $2^{\circ}$ anos do ensino fundamental está sendo implantado e testado em uma escola particular de grande porte em Salvador. E um outro projeto piloto de ensino de francês e espanhol com crianças a partir de 2 anos de idade está sendo organizado na Creche e no Centro da escola básica da UEFS.

\section{REFERÊNCIAS}

BEACCO J-C. Elaborer des politiques linguistiques éducatives en Europe, Le Français dans le Monde, 2003, pp.330, 18-20.

BRASIL. SECRETARIA DE EDUCAÇÃO FUNDAMENTAL. Parâmetros curriculares nacionais terceiro e quarto ciclos do ensino fundamental: língua estrangeira. Brasília, DF, 1998. 
GROUX D. Le meilleur âge pour apprendre. Le Français dans le Monde, 2003, pp.330, 23-25.

HAGEGE C. L'enfant aux deux langues. Paris: Editions Odile Jacob, 1996. 
